\title{
A Framework for the Africanisation of the Information Systems Discipline
}

\section{Jan Hendrik Kroeze}

\section{Abstract}

There is currently a worldwide debate about and drive towards the decoloniality of academia. Little research has, however, been done about the Africanisation of software design and development approaches. Information Systems research methodologies have not yet been enriched extensively by African perspectives, either. Although the Information and Communication Technology for Development (ICT4D) community has contributed significantly to the implementation of software in African contexts, the Information Systems discipline (IS) should be enriched - from an African perspective - on deeper, theoretical levels than those that have already been explored and implemented. This article aims to fill the need for a framework to guide the Africanisation of the IS discipline. The article follows a conceptual approach. It reflects on the opportunities for theoretical knowledge regarding the indigenisation of IS tuition, research, academic administration, community service, and the staff and students involved. These ideas converge into an integrated, two-dimensional graph. The proposed framework could serve as a starting point to extend the Africanisation process in the IS discipline, as well as to contribute to meta-theoretical discussions about the process itself.

Keywords: Africanisation, decoloniality, indigenisation, Information Systems, computing, conceptual framework

\section{Introduction}

There is currently a worldwide debate about the decoloniality of academia. This debate is especially relevant for postcolonial countries such as Australia, New Zealand, India and South Africa. Parallel to this debate is a drive towards the internationalisation of the tertiary sector. Although decoloniality and 
internationalisation may seem like opposing forces, the last-mentioned is not a synonym for globalisation or westernisation and actually creates room for the integration of indigenous knowledge and research approaches into mainstream teaching and research. In the Information Systems discipline (IS), a substantial body of research regarding Information and Communication Technology for Development (ICT4D) exists, and one should give credit to many researchers and practitioners who have already made significant contributions towards the use of information and communication technology (ICT) to improve Africans' lives. However, less research has been done about the Africanisation of software design and development approaches. ICT can be Africanised on various levels: current technology can be adapted or 'translated' to suit and serve African communities, or the technology itself could be redesigned or adjusted (Lotriet \& Matthee 2007). This is, in fact, the goal of the ICT4D 2.0 project (Bidwell et al. 2014). IS research methodologies have not yet been enriched extensively by African perspectives either. There is, therefore, a need for a holistic, theoretical framework that could guide research regarding the Africanisation of the Information Systems discipline in all its diverse layers. Such a framework could set the agenda for decolonial computing from an academic viewpoint: 'the scope of decolonial computing extends beyond the critique of ubicomp - and HCI [human-computer interaction] more generally ... to include various other fields within computing, such as AI [artificial intelligence] and robotics, ICT4D, software and hardware design, and data science and data analytics among others' (Ali 2016: 21). Decolonial computing is needed to incorporate indigenous ontology and epistemology into the deepest layers of computing theory and practice. Jansen (2017a: 13) calls for more black doctoral students and professors who can produce 'intellectually imaginative' Afrocentric knowledge and theory that can be included in tertiary curricula. At present, just a few IS studies have been done in this regard, as is illustrated by searches using the keyword 'decolonization' on the digital libraries of the ACM (https://dl.acm.org/) and AIS (https://aisel.aisnet.org/). A framework could go a long way to provide a roadmap to guide the IS guild to move into this space that unlocks fascinating possibilities for innovative and relevant research, teaching and community engagement. While one should be careful to not only address matters with mainly symbolic value (cf. Jansen 2017a), one should acknowledge that the whole spectrum of the academic project should receive attention. This ranges from designing technical support systems for other decolonising projects, such as alternative database architect- 
tures to store indigenous knowledge and artefacts (Hajibayova et al. 2016), to philosophical research regarding the essence of computing itself, such as reflecting on ubiquitous computing as a neo-colonial manifestation (Dourish \& Mainwaring 2012).

In order to fill the need for a framework to guide research on the Africanisation of IS, literature from postcolonial, especially English-speaking countries is explored to glean theoretical principles, while some broader international sources are referenced to demonstrate the international reach of the decoloniality debate. Recognition is given to existing research, especially regarding ICT4D and perspectives on IS teaching in South Africa.

Since end-user computing has become globally pervasive, research is necessary to develop scholarship, capacity and leadership to infuse information technology with African content in order to promote a decolonised digital environment for the continent. Technology is one component of indigenous knowledge systems, along with cultural, social, legal and educational aspects (Msila 2009). IS deals with organisational and social aspects of information technology, implying that this Computing discipline is the most suitable to deal with Africanisation in the IT field on a theoretical level. The article follows a conceptual approach. Decoloniality principles from national and international levels are applied to IS within the South African context. No empirical data is presented because the proposed framework is the result of theoretical reflection. According to Gregor (2006), research that develops a framework can often be regarded as an analyzing theory that describes and categorises the elements of a certain phenomenon. The IS Africanisation framework presented below uses the four pillars of academia as fundamental dimensions to categorise various endeavours of the subdiscipline. It follows an inductive approach and aims to provide a holistic overview. Since relatively little is currently known about the field, it contributes to our knowledge by providing a clear delineation of the various aspects that could be studied.

The article is structured as follows: after exploring external factors impacting the Information Systems discipline, the four main pillars of academic activity are used as a foundation for the framework, i.e. teaching and learning; research and postgraduate supervision; community engagement; and academic citizenship. Another item is added to these four, namely the people involved and affected by the indigenisation process. After exploring these fundamental building blocks of the framework, the anticipated effects of the Africanisation endeavours and internationalisation of the IS discipline are 
discussed. Relevant concepts from the Association for Computing Machinery (ACM)/Association for Information Systems' (AIS) syllabuses are integrated with theoretical notions found in the national and international literature on the indigenisation of higher education. Figure 1 offers a graphic representation of the fundamental structure of this article.

EXTERNAL IMPACTING FACTORS

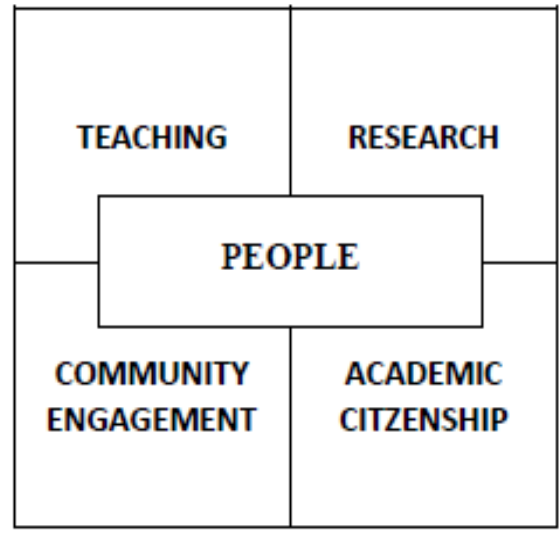

\section{IMPLICATIONS}

\section{Figure 1. The Fundamental Building Blocks for a Framework regarding the Africanisation of the IS Discipline}

Following the detailed discussion of the various aspects, the basic skeleton of the framework is populated by adding the main points to the relevant building blocks. The final integrated, two-dimensional theoretical framework serves to summarise the main points of the reflection and to give a holistic overview of the preceding sections, serving as a roadmap for the Africanisation of IS. It should, however, be noted that a cartographer is not a neutral person and drawing up a map implies selection and simplification based on philosophical assumptions and political powers (Prinsloo 2016). The same is true for the redesign of IS syllabuses and the rest of the IS agenda. The author, therefore, hopes that the proposed framework will serve to stimulate further debate and discussion regarding the Africanisation of IS and that other scholars and postgraduate students will further enhance it by using it, testing it, revising it and complementing it. 


\section{External Factors Impacting on the Africanisation of the IS Discipline}

Information and communication technologies are often used to improve the circumstances of disadvantaged communities. ICT4D has done remarkable work in this regard (see, for example, the comment on the Abalobi project below). Yet, they also often continue carrying forth the colonial values of the past in an unobtrusive way: '... IT might unobtrusively carry in it assumptions and practices that derive from that epoch [the colonial era in India]' (Gopal, Beaubien \& Marcon 2002: 525). In fact, western logic (esp. Wittgenstein's binary philosophical logic) lies at the core of the digital computer (Gruner 2016; Zemanek 1966; 1974). While information technology, on the one hand, can be seen as a black box with seemingly magic solutions for the developing world, it could also, on the other hand, be regarded as a trojan horse or can of worms that could cause havoc in indigenous cultures (Gopal, Beaubien, and Marcon 2002: 526).

Information technology, therefore, plays a vital role in the globalisation of the world, albeit in an inconspicuous way. From the perspective of Actor-Network Theory's concept of actants, IT can be seen as a non-human entity that replaces human agents imposing colonial values and agendas. These are built deeply (unknowingly or deliberately) into seemingly innocuous software and hardware (Csikszentmihalyi et al. 2018), while the value-laden technology is often accepted without questioning by colonised and postcolonial communities. Technology often undermines and replaces indigenous industries (Gopal, Beaubien \& Marcon 2002). Phronesis, i.e. plausible reasoning or the act of judgment, can be used as an academic approach to explore the role of values in the IS discipline (Ngwenyama \& Klein 2018).

Using existing technology in innovative ways to develop postcolonial communities is therefore only a first step towards decoloniality. Eventually, alternative technologies that are infused with indigenous knowledge and values should be developed, in order to facilitate 'technological dialogues' rather than mere transfer (Gopal, Beaubien \& Marcon 2002). This opinion is not only valid for postcolonial India but is also relevant within the current decolonisation and Africanisation debates. The term Africanisation has strong political roots. Kawawa (1960) uses it to refer mainly to social and economic redress of the postcolonial era. He uses the term African inclusively for black people and 
other groups who are identifying themselves with the continent and its struggle for freedom in all these aspects.

It should be noted that identity is not a fixed phenomenon, but diverse and fluid. A process of Africanisation, therefore, should first acknowledge that there is no single African culture, ontology or epistemology, but a plethora or constellation of identities (Prinsloo 2010). Building indigenous knowledge and ubuntu values into ICT can protect Africa from replacing colonialism with an 'itocracy' (domination by western-infused IT) while still using the technology to advance and disseminate African cultural products (Phahlamohlaka \& Kroeze 2005). Belief systems, such as organisational culture, language, gender and religion all influence technology and the adoption thereof, but are also influenced by technological progress. Phahlamohlaka and Kroeze (2005) suggest various ways in which information systems can be Africanised, including proposals regarding education, to change perceptions about IT and careers in IT. For example, African computer games could be used to stimulate computer literacy and digital skills from early childhood on. ICT is also needed as a facilitator to capture, store and disseminate indigenous knowledge (Lotriet \& Matthee 2007).

The divergent roles of ICT prompt the core question underlying this article - why do scholars need a theoretical framework for the Africanisation of the IS discipline? We need a holistic framework because the decolonisation of tertiary education is not a linear process (Prinsloo 2016). It is a multidimensional movement affecting staff and students, tuition and research, academic citizenship and community engagement. A framework (or a model, or a map) could provide some guidance and oversight in this complex scenario. It may help academics to avoid disciplinary chauvinism (western-centrism) (Manathunga 2009) on various levels of scholarly work, and to extract and develop exemplary and respected aspects from indigenous knowledge systems that could coexist with western knowledge (Msila 2009).

According to Jooste (2015), South Africa's higher education has been eurocentric even in the post-colonial and post-apartheid era after 1994. Yet, due to the high quality of the country's tertiary sector, a significant cohort of postgraduate students is attracted to study at South African universities towards master's and doctoral qualifications. Jooste's historical overview mainly deals with operational matters and is silent on the indigenisation of the content of tertiary syllabuses. The rest of this article aims to fill in some of the gaps in terms of the academic project. The article acknowledges that ethics and values 
are deeply embedded into all aspects of higher education and will, therefore, include a brief reflection on the possible inclusion of ubuntu values. Although the idea of humanism is not unique to Africa and is implicit in many other cultures, the unique African version (ubuntu) should be explored in more detail as the guiding value underlying the IS discipline on our continent.

Before moving on to the four pillars of academic work in IS, a note should be made about the tension between globalisation and localisation in Computing schools and departments in South African universities. The international ACM/AIS computing curricula are regarded as the gold standard to strive for. Since IS departments try to adhere to the standards set by global accreditation bodies on the one hand, they should - and they do - take into account the local and business context on the other hand (Ponelis et al. 2012). Although the international guidelines for IS syllabuses leave room for the cultivation of intercultural skills during undergraduate and postgraduate programmes (Topi et al. 2010, 2017), the dominating effect of western textbooks may leave little room for deep integration of indigenous inputs into these curricula. While the drive towards Africanisation impacts on the IS discipline in one direction, it is counteracted by the homogenising drive of globalisation.

\section{Africanising Information Systems Teaching and Learning}

In the post-colonial era there is internationally a realisation that indigenous bodies of knowledge and heritages can and should be used not only to amend undergraduate teaching but also to enrich traditional eurocentric research topics and pedagogical supervision approaches (Carter et al. 2018; Harvey \& Russell-Mundine 2018; Letsekha 2013). Lecturers should investigate indigenous knowledge systems (IKS) for relevant knowledge that could amend undergraduate content. IKS conserves the accumulated knowledge of various generations, incorporates a communal way of learning and makes adjustments in what people know to promote further development (Msila 2009).

Generally speaking, taking into account learners' cultural background during tuition activities makes teaching and learning more efficient (Msila 2009). Specialised modules can be introduced to enable the acquisition of cultural competence. For example, a signature module in undergraduate Computing qualifications that is compulsory for all first-year students could improve the status of indigenous knowledge and generate mutual respect between diverse cultural groups. Giving specific attention to diverse cultures 
may also improve the success rates of students from indigenous communities (Harvey \& Russell-Mundine 2018; Letsekha 2013). Jansen (2017a: 12) argues that it is not sufficient to Africanise the content of the curriculum but that the interaction between lecturer or supervisor and student ('the critical engagement with knowledge between teachers and students') is equally important.

With reference to the IS discipline, the principle of Africanisation can be applied, for example, by including and integrating African traditions to inform the theory and practice of IS as an approach to decolonise computing (Ali 2016). One wonders how systems analysis design, business process management and joint application development approaches could be enriched and adapted by integrating the principles and customs of conventional African decision-making processes such as indabas, imbizos, lekgotlas and bosberade (see https://gqom.wordpress.com/2016/11/20/how-sae-words-for-meetingsof-people-have-gained-new-meanings-in-the-21st-century-imbizo-indaba;ekgotla/ for the differences between these types of meetings). In fact, one of the high-level capabilities in the IS2010 curriculum points precisely in this direction: 'Customize [organisational] processes to address cultural and ethnic needs' (Topi et al. 2010:17).

Indigenous content can also be integrated into the practical parts of disciplinary modules such as teaching case studies with an African context used for programming exercises. In IT service management modules, theoretical concepts can be applied to and adjusted for African business environments. In modules that teach computer literacy, material regarding African culture and ethics can be used to practise Word processing, digital presentations (slideshows), and data manipulation (spreadsheets, databases).

Postgraduate research supervision is often regarded as part of lecturers' tuition duties but also as part of their research projects. The research aspects will be discussed in the next section, but in terms of the act of guiding students, some of the lessons learned from indigenisation research in New Zealand regarding Maori and Pasifika cultures may resonate within an African context as well, e.g.:

- Making use of cohort support groups to simulate a family or community environment;

- Involving the larger family and community in a postgraduate's journey; and

- Being aware that patterns of thinking may differ (Carter et al. 2018). 
While distance education is usually regarded as more challenging than residential models, it could also create an opportunity to involve a postgraduate student's immediate social circle more easily. In South Africa, most master's and doctoral IS students study part-time, which is challenging in terms of time constraints but allows more family and social support during their research journeys. Students should be urged to 'cash in' on the hidden benefits of parttime, off-campus studies.

Supervisors should train and prepare postgraduate students to do research in intercultural environments by teaching them that knowledge is socially constructed within political environments and can, therefore, be challenged. It is not merely a linear process of accumulating more and more facts (Manathunga 2009). It should be acknowledged that western knowledge is not universally true, rational, objective, neutral and colour-blind (Harvey \& Russell-Mundine 2018; Tsey 2010). Preparing students to be open to alternative voices will also enhance their ability to think critically and to synthesise divergent pieces of knowledge in their own thinking. Villagisation (collective learning) could be explored as a way to integrate how Africans learn and create knowledge, and to accommodate indigenous values and beliefs (Msila 2009). Where possible, study groups and team supervision can be used to facilitate villagisation on postgraduate levels.

The language of tuition should receive more attention. In South African universities there is a persistent move towards using English exclusively as the medium of teaching. This transformation is true especially of computing modules which often are the first to switch to single medium (English) classes even in double medium universities. While it is true that IS students will work in environments where English terminology dominates, the creation of multilingual glossaries and vocabularies may be a good starting point to develop subject terminology for indigenous languages and to assist inexperienced students in getting to grips with their new fields of study. Mamdani (2018: 4) refers to Afrikaans as a successful decolonising attempt to include a minority language in mainstream academia (rather than displacing English), but it must be noted that Afrikaans is disappearing very fast in the South African higher education environment. Although it may sound rather superficial to just use native languages in tuition, language plays an essential part in how people perceive and express themselves. 'Addressing the politics of language that structures and owns collective and personal identity, is, therefore, integral to decolonizing HCI' (Bidwell 2016: 4). Local language is 
the carrier of indigenous ontology and epistemology and should, therefore, be used to ensure knowledge diversity underlying and built into Africanised information systems (Aludhilu \& Bidwell 2018).

Africanisation can also be implemented in non-degree programmes. The ICT labour force often needs reskilling to keep up with new technologies and developments in the sector. Formal education is often overinstitutionalised and does not allow agile adaptability to these disruptive forces. Short learning programmes can be used as transitional or reskilling courses to make new graduates industry-ready by refining and polishing their basic computing knowledge for current markets, to repurpose existing ICT workers' talents, and to attract more raw talent to address ICT skills shortages. Mobile technology courses, for example, could be used as a reskilling platform that simultaneously stimulates entrepreneurial activity (Breytenbach, De Villiers \& Hearn 2013). Short courses could also be an ideal instrument to provide training to address changing academic priorities, such as indigenisation, decolonisation and Africanisation of computing and IS.

The tuition-related suggestions above call on African IS scholars to address decolonisation of the IS curriculum on a broad theoretical level, and this could especially be researched by IS educationalists and IS philosophers. Since tuition on tertiary level is ideally interwoven with research and community engagement, some aspects related to teaching will be discussed in the sections that follow below.

\section{Africanising Information Systems Research}

In the postmodern and postcolonial era, researchers often have to operate in many cultural layers (Manathunga 2009). Although challenging, this scenario also provides opportunities for new approaches towards research and to question underlying ontological and epistemological assumptions. Diversity stimulates creativity (Harvey \& Russell-Mundine 2018; Letsekha 2013). IS scholars and publication gatekeepers should reconsider whether empirical research is the only valid research type accepted for publication and how conceptual research could also be seen as 'original' and valid. Meta-theoretical reflections on Africanisation will be conceptual by nature and deserve equal publication opportunities. Western epistemology allows and encourages selfcriticism and therefore has room for interrogation and revision, also from an African perspective (Harvey \& Russell-Mundine 2018; Popper 1981; Popper 
\& McIntyre 1983). 'Critical self-reflection is an especially useful decolonising tool as it asks us to interrogate our assumptions about what knowledge is assigned value in our institutions and why. It can help students (and staff) identify the deep colonising tendencies of individuals, groups and institutions by making visible those theories and practices that seem "natural" but which in reality might be harbouring injustice and racism' (Harvey \& RussellMundine 2018: 10). At the same time, contributions from indigenous knowledge systems should also be subjected to academic reflection and critique. Scholars should be critical about indigenous knowledge pieces and guard against romanticising it blindly (Msila 2009).

The most obvious way to Africanise IS research is to find research topics within the African context, and one can assume safely that many local research projects are already doing this. Indigenous knowledge should be seen as a source of valid topics that could contribute to existing scientific knowledge (Carter et al. 2018). This perspective opens a new research area in Information Systems that is still relatively fallow: how can African technology and knowledge be used in the discipline to enhance learning and to enrich the content and methodology of software development and research?

An academic transculturation (reciprocal acculturation) process should take place to integrate disciplinary and indigenous pieces of knowledge that both appreciate and critique the foundations of all these academic cultures (cf. Letsekha 2013). Africa can learn from the west and determine what can be absorbed and how it can be used, but the enrichment should go both ways in order to ensure an exchange and a merging into a new hybrid knowledge (Manathunga 2009).

A process of indigenisation can be complicated in natural science disciplines, but even here the underlying values and theoretical assumptions can be explored, e.g. acknowledging that the digital computer is built on a western philosophical concept of binary logic (as mentioned above) or that the structure and metadata of databases reflect specific cultural values, albeit often unknowingly (cf. Harvey \& Russell-Mundine 2018). Ali (2016) sees computing as a colonial phenomenon per se since it carries Western principles of liberalism and modernity. According to Ndlovu-Gatsheni (2018) African scholars should be given the opportunity to address the deep ontological and epistemological issues in academia by 'rethinking' and 'unthinking' the eurocentric model that they are trained in. Within the IS domain, Lotriet and Matthee (2007) agree that the ontological and epistemological assumptions 
underlying technology could be exposed and replaced, and even lead to paradigm shifts.

Mamdani (2018) pleads for an African intellectual mode of reasoning. He believes that it is more difficult to change the way one thinks than to change one's ideology. The process of reasoning is deeply infused by one's educational culture and is still often dominated by western modes (e.g. English vs. German vs. French ways of reasoning). 'Most African academics have accepted the definitions and prescriptions of the west as the template of their world outlook' (Maserumule 2015). There should be an awareness that patterns of thinking may differ, e.g., in New Zealand, metaphors - rather than theories - are often used by the Maoris to conceptualise (Carter et al. 2018). An African mode of reasoning should be infused in African traditions and frames of reference, 'one which weaves together a set of discourses communicated in a common language that presupposes - or suggests - an intellectual community with a long historical formation' (Mamdani 2018: 4). For example, 'unraveling the mathematical and scientific skills embedded in indigenous technologies and cultural practice of the African majority' could address the current backlog in these knowledge fields (Msila 2009). An ubuntu-informed philosophy of science could be another way of Africanising science on a profound theoretical level. However, such an ubuntu philosophy of science should also be subjected to academic criticism and should not be seen as a magic wand that could Africanise and sanitise all knowledge in one sweep (Prinsloo 2010).

An example of Africanising the theory of IS can be found in Tsibolane (2016). Tsibolane acknowledges important work that has been done by ICT4D researchers to improve the living conditions of poor communities in Africa but believes that the theoretical foundations of this work need to be enriched from the perspective of ubuntu to put more focus on the social interdependency and wellbeing of these communities. He suggests an approach of frugal IS innovation to maximise the impact of technology while minimising complexity, cost and impact on the environment. In his proposed theoretical framework, ubuntu replaces the more individualistic western theory of social capital to integrate collective capabilities to the epistemology of critical IS research.

Not only the philosophical aspects should be reflected on, but research methodologies and industry research methods could also be transformed (Lotriet \& Matthee 2007; Manathunga 2009). Ordinary talk often leads to more authentic data gathering (within an indigenous New Zealand perspective) - this may indicate that unstructured interviews could be a better approach than 
surveys and structured interviews in indigenous environments (Carter et al. 2018). An inclusionary, reflective approach also proved fruitful for research with the Yarrabah community in Australia (Tsey et al. 2002). Tsey (2010) used a local Ghanian custom of moderating narrative accounts repeatedly to gain maturity and consensus in empirical data. This approach could be regarded as an Africanised alternative for unstructured interviews or focus groups, and a way of 'blending western and African methodologies' (Letsekha 2013).

Critical research has become an established philosophical point of departure for IS research (Myers \& Klein 2011; Oates 2006). Tsibolane and Brown (2016) extend Myers and Klein's principles by synthesising them with concepts in postcolonial theory to create a new theoretical framework that can be used for emancipatory IS studies in Africa. The inclusion of ubuntu in software such as stokvel applications provides a relevant example of African values that are built into technology, as well as IS research about this phenomenon. A stokvel is an African community-based saving mechanism. Biyela, Tsibolane and Van Belle (2019) used domestication theory to study the use of ICTs by stokvel groups. They found that very basic technology is usually implemented. However, a search on Google Play on 1 February 2019 listed at least four stokvel apps that could be downloaded. More research is needed to explore the reasons for non-adoption of available custom-built software solutions and ways to improve trust in and acceptance of these Africanised technologies. However, another app, Abalobi, that assists local fishermen in the Western Cape, did prove to be successful ${ }^{1}$.

The difference in uptake between these two applications raises new research questions for IS, e.g., how could lessons learned from the Abalobi project be applied to stokvel apps to improve adoption, and what theoretical insights can be derived from these projects and their differences?

Ethical issues have been receiving more and more emphasis in academia over the past few decades. The prevention of plagiarism and publication in accredited, reputable journals is high on the agenda of tertiary institutions in South Africa. Postgraduate students and scholars are required to obtain ethical clearance before conducting any empirical work and even sometimes for conceptual work. However, one should acknowledge that ethical values are also culturally relative. The implications for how we do research and what counts as acceptable results are enormous, but little work has been done to

${ }^{1}$ https://twitter.com/carteblanchetv/status/1002180395180290048?lang=en 
explore the integration of African ethics into the ethical requirements of higher education institutions. There is a need to find an inclusive and shared set of ethical principles (Harvey \& Russell-Mundine 2018).

The next section deals with community engagement where many of the above-mentioned research principles may also be applicable and could, ideally, be implemented in projects that integrate the various pillars of the academic endeavour.

\section{Africanising Community Engagement Related to the IS Discipline}

Community-engagement projects can be Africanised by indigenising development principles. IS scholars should not only focus on disciplinary and interdisciplinary solutions for the needs of disadvantaged groups but should include traditional values and decision-making methods in their projects. In an Australian context, listening, respect, and the building of relationships and interconnectedness are important concepts to ensure successful interventions, and this may be true in an African context too (Harvey \& Russell-Mundine 2018). With reference to Aboriginal Australia and rural Ghana, Tsey (2010) calls for relevant social science to overcome inequality and poverty in deprived communities by building on their cultural strengths while addressing harmful aspects. This empowerment could be attained by grounding development projects in the ethical values and constructive traditions of the affected groups. Participatory action research is a suitable approach to facilitate empowerment projects that are grounded in local customs (Tsey et al. 2002).

The role of the community is very important in African contexts. Breytenbach and de Villiers (2012) indicate that the community plays an important role to motivate high school learners to consider a career in ICT. Especially parents and teachers, and to a lesser extent, other family members, role models and friends are indicated as primary motivators that influence learners' study choice. Africanisation attempts should include rectifying employment equity profiles in the ICT sector. The community should, therefore, be adequately informed about ICT as a dream career to recruit more candidates from historically disadvantaged groups for the field. More qualified information technologists should, in turn, lead to more competition resulting in the growth of the sector and the creation of more job opportunities.

Community engagement can also be used as a bottom-up approach to 
inform researchers on a grassroots level about indigenous knowledge that stands alongside western bodies of knowledge, to identify areas of research and to evaluate if and how completed research impacts the communities. Reciprocally, community development is also a form of academic praxis (Tsey et al. 2002; van der Westhuizen, Greuel \& Beukes 2017). Only a deep involvement with local communities can show researchers and practitioners the way to build software around indigenous communities' values and needs, rather than expecting them to adjust their software requirements to adhere to the limitations of technology (Lotriet \& Matthee 2007).

\section{Africanising Academic Citizenship and the Role of People Involved in the Africanisation of the IS Discipline}

Academic citizenship refers to the administrative and professional role played by academics inside and outside their institutions. These duties include management tasks and involvement in academic societies, as well as endeavours to build and maintain their disciplines, such as peer review, external examination and moderation of examination papers and scripts. This aspect of academia is closely related to the central role that people play in Africanisation. Therefore, the two elements will both be discussed in this paragraph (although separated in the suggested framework.)

Before discussing matters of academic citizenship, it should be noted that the sub-discipline of Human-Computer Interaction (HCI) is one of the few areas in IS that has already spent considerable energy on the decolonisation and Africanisation of the field. On the ACM's digital library alone, one can find more than 40 studies dealing with various aspects of decolonisation, including more than 20 focusing on HCI and related design matters (as of 1 June 2019). This trend, that is reflected by the dedicated AfriCHI conferences (cf. Awori et al. 2016; Bidwell et al. 2016), warrants a follow-up study that investigates the Africanisation of HCI in more depth, but in this article a few pointers will have to suffice. Bidwell (2016) believes that, since traditional computer technology mostly represents whiteness, the world needs a concerted effort in HCI to redesign technologies to integrate and 'reframe' African identities. This process will not only make technology more accessible for Africans, but could Africanise technology itself on a deeper level. It could show the world innovative ways to de-objectify people in an e-world where people are often reduced to fit the limited categories of digital technology. 
Csikszentmihalyi et al. (2018) investigate the impact of political and economic realities on technology acceptance in sub-Saharan Africa, as well as the obligation which the HCI discipline has to take these factors into account when researching the design of Africanised information systems and mobile applications. Nwokoye et al. (2016) propose a research agenda for the indigenisation of agent-based modelling and social computing. They call for interdisciplinary collaboration between social scientists, computer scientists and human-computer interaction specialists to account for unique African cultural characteristics, such as African thought processes and conceptions of time and personal space, in information systems using simulations. This could enhance the usefulness and user experience not only for humans in Africa but also improve human-robotic interaction. Aludhilu and Bidwell et al. (2018) highlight the importance of including local language in technology design to ensure a suitable mapping between indigenous social and intellectual qualities and custom-made software. Software designers should also take into account intergenerational differences regarding communication needs and skills when they design social media for diverse communities (Bidwell et al. 2014).

Due to the legacy of racial segregation in South Africa, leadership roles in academia were mostly taken up by whites until 1994. Since then concerted efforts have been made to change the profile of academia to reflect the composition of the population, but due to direct competition with industry for staff, the IS field still has a long way to go. Academic leaders in the field could contribute to this process of redress by creating academic citizenship opportunities for colleagues from previously disadvantaged groups, and by mentoring emerging scholars to be ready to fill their shoes. Furthermore, directors and heads of departments should increase African staff cohorts and ensure Africans' participation in leadership and management. Infrastructure and resources should be given to support Africanisation initiatives (Harvey \& Russell-Mundine 2018; Letsekha 2013).

Other people involved in and affected by the Africanisation of the IS discipline are undergraduate and postgraduate students, and administrative staff. The presence of diverse academic staff members prepares students of all ethnicities better for work in a multi-ethnic industry environment (McLaurin, Carte, \& Randolph 2015). It could enhance the throughput of black students (as in the USA) and bring fresh ideas into the academic arena. Mentors from historically disadvantaged groups are essential to assist students from these communities with academic transition problems and to educate undergraduate 
and graduate students regarding the benefits of an academic career in IS (McLaurin, Carte, \& Randolph 2015). Africans need African role models and mentors to revise educational practices and to change stereotype perceptions about ICT (Phahlamohlaka \& Kroeze 2005). Supervisors should learn about indigenous world-views from their students, and there should be mutual respect for each other's background; the relationship should be more familylike than contract-like (Carter et al. 2018).

It may be asked if and to what extent scholars who are descendants of colonisers or settlers are entitled to participate in and contribute to the debate of decolonisation. Is there only room for black academics to decolonise the curriculum (cf. Jansen 2017a; 2017b), or can brown, Indian and white people contribute too, and how? There is a tension between the need for whites to participate in these discussions and the extent to which their contributions could be regarded as valid by historically disadvantaged groups. However, even if they were not guilty of participating in suppression themselves, they could and should accept the responsibility to work towards reconciliation. Although the process of unlearning and relearning may cause some discomfort, finding solutions to redress the inequalities of the past can be facilitated (Harvey \& Russell-Mundine 2018). According to Behm Cross (2017), fictionalised vignettes (real incidents retold as anonymised stories) can be used to stimulate debates on 'whiteness' in academia in the USA. Whiteness (the North-American equivalent of Eurocentrism) and neoliberalism are pervasive in subtle and explicit ways in Northern American academic circles but are often not discussed because they are assumed to be the only correct and standard form of science. This attitude manifests as direct opposition to calls for indigenisation, weak attempts to make room for alternative viewpoints, or even obliviousness towards discrimination and the possibility of different academic cultures and approaches.

With reference to Fashion Studies, Waldron (2017: 17) refers to 'the apparent paradox of stylistic borrowing from the west as homogenisation, and by the west as appropriation'. This theme may be relevant for other academic fields, including IS, too, when scholars debate the question of who is allowed to participate in the Africanisation project, in discussions about the westerncentrism of ICT and the adoption of African-centred information systems by the rest of the world. Scholars who are from indigenous communities and who have been trained in western-based disciplines may have internalised deep colonising principles and should therefore also work purposefully to complement 
western knowledge with a variety of indigenous stores of knowledge (Letsekha 2013).

\section{The Anticipated Effects of the Africanisation of the IS Discipline}

In the introduction globalisation was briefly mentioned as an opposing force to localisation. Some scholars use internationalisation as a synonym of globalisation (cf. Lotriet \& Matthee 2007) while others emphasise the cultural diversity aspect of globalisation (Rizvi \& Walsh 1998). This article differentiates between the idea of globalisation as a homogenising force (usually toward western dominated knowledge) and internationalisation as an attempt to diversify knowledge by enriching current bodies of knowledge with alternative contributions originating in minority knowledge cultures, such as indigenous knowledge systems (Dzvimbo \& Moloi 2013). Internationalisation thus becomes the result of localisation or Africanisation - it describes the contribution made by indigenous knowledge systems to the worldwide encompassing body of knowledge. New knowledge creation embedded in the local cultures is seen as one of the envisioned outcomes of internationalisation (cf. Jooste 2015). 'Internationalisation takes strong cognisance of the local culture, that, without the local, there would be nothing to offer the other and so a strong local culture would enhance the value of internationalisation' (Letsekha 2013).

Like in other disciplines, students should be prepared to work and operate efficiently in a global context. While globalisation is, therefore, a strong force to be reckoned with, internationalisation is an encompassing drive that also has room for indigenisation. 'If we are to internationalize learning, we must do that within the context of the different cultures and practices of knowing, doing and being in the disciplines' (Leask 2015: 3). Not only the formal curriculum but also the informal and hidden curricula are at stake. Leask's (2015) conceptual framework for the internationalisation of the curriculum puts disciplinary and interdisciplinary knowledge in the centre of a series of expanding concentric circles. Knowledge is contained in four levels of context, i.e. institutional, local, national and regional, and global. Other relevant dimensions are the philosophical paradigms that are valid for disciplines, and professional requirements. All these aspects should be taken into account when a curriculum is internationalised in terms of teaching, learning and assessment. Africanisation speaks to the institutional, local, 
national and regional levels where African paradigms and perspectives should be accommodated. Ridings, Simpson, Leask et al. (2008) developed a taxonomy of intercultural competence that integrates various intercultural domains with teaching and learning levels in a two-dimensional graph (cf. Leask 2015: 65). Since their tool was primarily developed for business disciplines, it may provide a holistic roadmap for IS which is often regarded as the business and management leg of Computing.

Africanisation can be seen as the African version of western postmodernism: 'Africanisation, from a postmodern perspective, can be understood and located as a mixture of cultural, political, economic, social, ontological and epistemological initiatives to celebrate the local, the particular, the distinctiveness of being African and being-in-Africa/from-Africa' (Prinsloo 2010, 24). Since cultures are permeable the process of enrichment between African and other knowledge systems should be bi-directional to form a synergy, and there should be a mutual appreciation for diversity (Msila 2009). Contributing to the Africanisation ideal, African academics are creating new knowledge stores of African knowledge in its own right, allowing an interplay of various knowledge systems. They are questioning and revising existing systems by superimposing unique African content onto other knowledge systems and integrating these diverse systems (Prinsloo 2010). Mamdani (2018) suggests that imported or assimilated western theories should be balanced with theories that theorise African realities. The integration of African and western knowledge to create a synergy could again lead to African-infused technologies that could be commodified for international markets (Lotriet \& Matthee 2007). Letsekha (2013) suggests that a process of endogenisation is followed rather than indigenisation. Endogenous knowledge is rooted in Africa and focuses its ontological and epistemological debates on local knowledge and ways of knowing. This process allows African knowledge to learn from the west but facilitates knowledge to grow and develop in Africa and to adapt to African conditions and needs. Endogenisation also creates room for inputs from all ethnic and cultural groups on the continent and facilitates the creation of local knowledge that can be shared internationally. It would be naive to believe that Western curriculum content can be replaced completely with exclusive African knowledge since our diverse world's knowledge has become entangled and integrated (Jansen 2017b).

One of the foundational competencies included in the ACM/AIS's guidelines for master's degrees in IS is intercultural skills that will enable 
graduates to serve international clients effectively and appropriately (Topi et al. 2017: MSIS-24). This skill complements other soft skills such as critical thinking and communicative abilities (De Villiers, Johnson, and Cremer 2012). In a multicultural country, this competency is even more important because it is also essential in the local context. This requirement leaves room for African IS scholars to do relevant research that could be used by the rest of the world by indicating what intercultural competencies should be taught and practised to operate successfully and appropriately on the continent. However, this competency should also be broadened for African IS scholars to make room for the inclusion of unique African content in the field. Only finding a way to apply western knowledge and technology acceptably and effectively could be seen as a sophisticated form of academic coloniality. The ACM/AIS undergraduate curriculum guidelines are more sensitive to the issue of cultural differences in global projects and teams. It is not only required as a foundational skill, but is also mentioned in areas such as project management, systems analysis and design, and business process management (Topi et al. 2010). Giving in-depth attention to these aspects in undergraduate and postgraduate IS syllabuses could contribute significantly to the internationalisation of the IS discipline.

\section{Conclusion}

To conclude, the details of the reflection regarding the international debate on indigenisation are converged into a two-dimensional graph that could serve as a roadmap for the Africanisation of the IS discipline (see Figure 2). The framework is organised according to the four pillars of academia, i.e. teaching; research; community engagement and academic citizenship. A fifth pillar, people, has been added in the centre of the graph to clearly demonstrate the central role that people should play in the Africanisation process, either as agents, participants or recipients. In the preceding discussion, ICT4D and HCI are highlighted as sub-disciplines within IS that have already given substantial attention to decoloniality and Africanisation, while guidelines are given to extend this endeavour to all aspects of the IS discipline. The framework also covers external factors that affect the Africanisation process, either by promoting it (localisation) or by working against it (globalisation). Finally, the framework accommodates the effects of Africanisation on the wider IS field. As a theoretical discussion, this article has some shortfalls (cf. below.). 


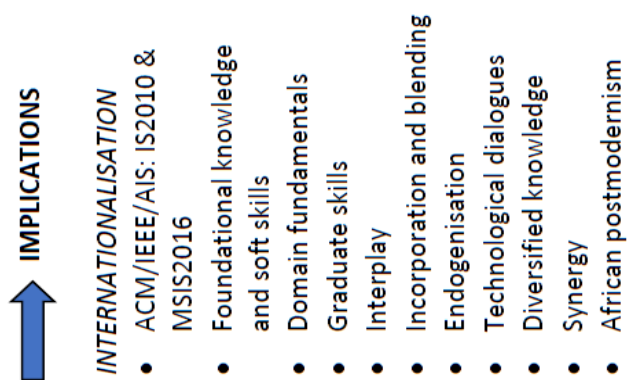

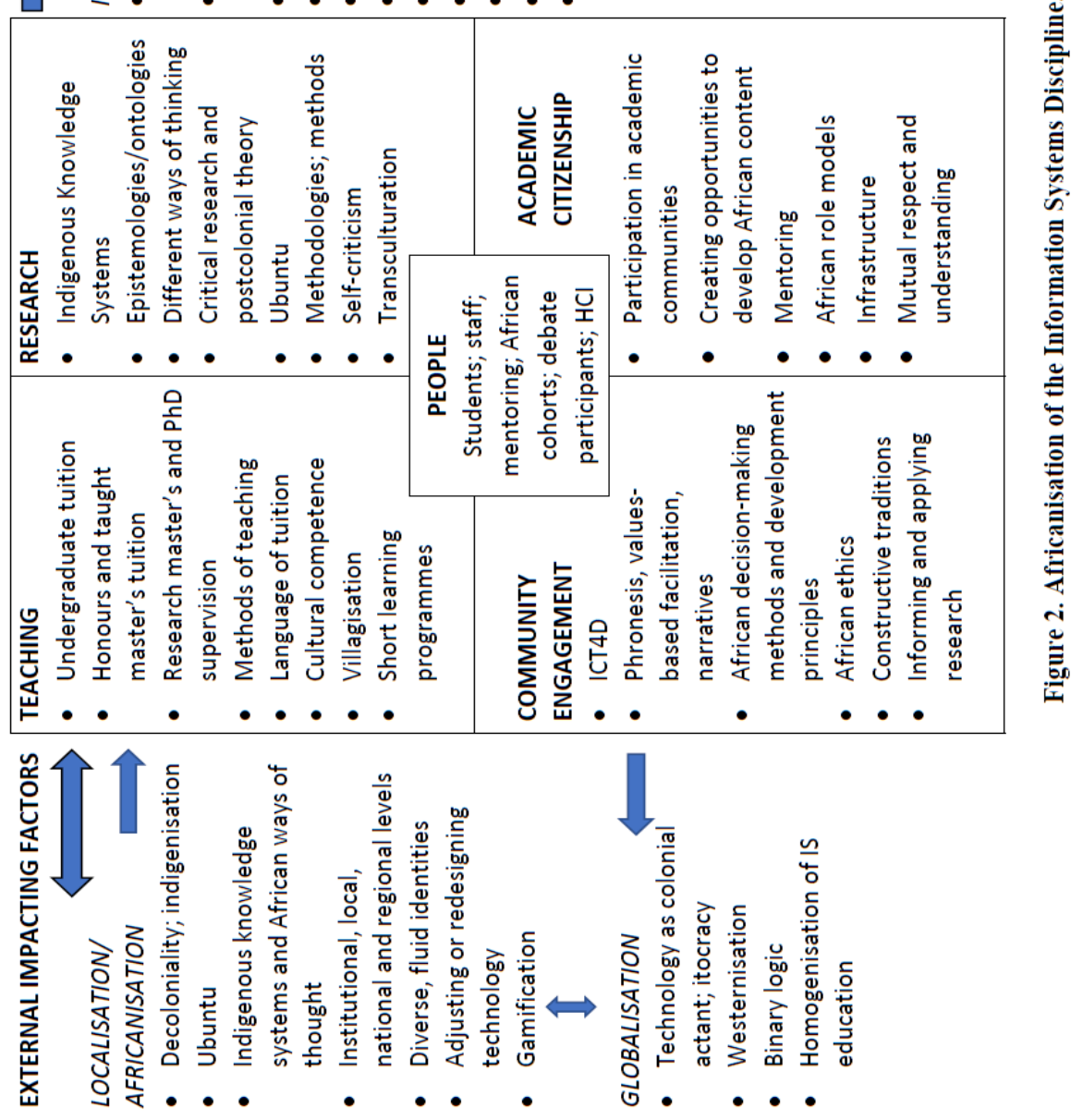


The article used a conceptual approach to obtain a holistic overview of the current status quo of decoloniality in IS. The proposed framework is not validated empirically, and this could be done in future work. The purpose of the current version is to stimulate debate and innovative research. More research is necessary to give a proper synopsis of existing work in the ICT4D and HCI fields. Barriers in public institutions that may hinder Africanisation of the discipline have not received attention in this article. Questions about the participation of private tertiary institutions with fast-growing student numbers and limited financial resources in Africanisation, open up fascinating new avenues for further studies that could not be dealt with in this article. The author also realises that ICT changes very fast. Spending financial and human resources on Africanisation of the IS discipline may affect or even hamper practitioners who have to keep up with the relentless global pace and competition. Further research could look deeper into this dilemma and try to suggest a way to balance the opposing forces while calculating the 'sacrifices' that will have to be made to realise the ideal of Africanisation.

The author believes that indigenisation should be seen as an internationalising agent for the diversification of software applications that are founded in an array of multiple realities and knowledge systems. This not only creates many new and innovative research opportunities but can and should enrich the discipline as a whole. The challenge for IS researchers on the African continent is to show the rest of the world how its rich cultural heritages can inform and transform the discipline. The challenge for the international IS discipline as a whole is to find a synergy between Western-driven knowledge and technology and alternative voices and approaches from other parts of the world.

\section{Acknowledgments}

The University of South Africa (UNISA) is acknowledged for granting the author a period of research and development leave during which time the article was written. The research was supported in part by UNISA and the National Research Foundation (NRF) of South Africa. Any opinion, finding or recommendation expressed in this material is that of the author, and neither the NRF nor UNISA accepts any liability in this regard. I would like to thank the editors and reviewers for their invaluable feedback that guided me to improve the article. 


\section{References}

Ali, S.M. 2016. A Brief Introduction to Decolonial Computing. XRDS: Crossroads, The ACM Magazine for Students 22,4: 16 - 21.

https://doi.org/10.1145/2930886

Aludhilu, H.N. \& N.J. Bidwell 2018. Home is not Egumbo: Language, Identity and Web Design. In Proceedings of the Second African Conference for Human Computer Interaction: Thriving Communities, 2:1 - 2:11. AfriCHI 2018, December 3 - 7, 2018, Windhoek, Namibia.

https://doi.org/10.1145/3283458.3283460

Awori, K., N.J. Bidwell, T.S. Hussan, S. Gill \& S. Lindtner 2016. Decolonising Technology Design. In Proceedings of the First African Conference on Human Computer Interaction, 226 - 228. AfriCHI'16, November 21-25, 2016, Nairobi, Kenya. https://doi.org/10.1145/2998581.2998622

Behm Cross, S. 2017. Whiteness in the Academy: Using Vignettes to Move beyond Safe Silences. Teaching in Higher Education 22,7: 879 - 87. https://doi.org/10.1080/13562517.2017.1340266

Bidwell, N.J., T.S. Hussan, S. Gill, K. Awori, S. Lindtner, N.J. Bidwell. T.S. Hussan et al. 2016. Decolonising Technology Design. In Proceedings of the First African Conference on Human Computer Interaction, 256 - 259. AfriCHI'16, November 21-25, 2016, Nairobi, Kenya.

https://doi.org/10.1145/2998581.2998616

Bidwell, N.J. 2016. Decolonising HCI and Interaction Design Discourse: Some Considerations in Planning AfriCHI. XRDS 22,4: 22 - 27.

https://doi.org/10.1145/2930884

Bidwell, N.J., S. Robinson, E. Vartiainen, M. Jones, M.J. Siya, T. Reitmaier, G. Marsden \& M. Lalmas 2014. Designing Social Media for Community Information Sharing in Rural South Africa. In Proceedings of the Southern African Institute for Computer Scientist and Information

Technologists Annual Conference 2014 on SAICSIT 2014 Empowered by Technology, 104-114. SAICSIT2014, September 29 - October 01 2014, Centurion South Africa. https://doi.org/10.1145/2664591.2664615

Biyela, N., P. Tsibolane \& J-P. van Belle 2019. Domestication of ICTs in Community Savings and Credit Associations (Stokvels) in the Western Cape, South Africa. Communications in Computer and Information Science (Springer, IDIA 2018) 933: 35 - 47.

https://doi.org/10.1007/978-3-030-11235-6_3

Breytenbach, J. \& C. de Villiers 2012. Supply Elasticity within the South 
African ICT Labour Market. In Proceedings of the Annual Workshop of the AIS Special Interest Group for ICT in Global Development 1: 1 - 28. https://aisel.aisnet.org/globdev2012/1/

Breytenbach, J., C. de Villiers \& G, Hearn 2013. Directing the South African ICT Labour Force towards Growth Sectors: A Case for Non-Institutional Scarce Skills Transition and Reskilling Courses. In AIS Special Interest Group for Education: International Academy for Information Management - AIS SIG-ED IAIM 2013 International Conference on Informatics Education and Research Conference. http://aisel.aisnet.org/siged2013/6 Carter, S., D. Laurs, L. Chant \& E. Wolfgramm-Foliaki 2018. Indigenous

Knowledges and Supervision: Changing the Lens. Innovations in Education and Teaching International 55,3: 384 - 93.

https://doi.org/10.1080/14703297.2017.1403941

Csikszentmihalyi, C., J. Mukundane, G.F. Rodrigues, D. Mwesigwa \& M. Kasprzak 2018. The Space of Possibilities: Political Economies of Technology Innovation in Sub-Saharan Africa. In Proceedings of the 2018 CHI Conference on Human Factors in Computing Systems 306: 1 306:13. CHI '18. Montreal, QC, Canada, April 21 - 26, 2018.

https://doi.org/10.1145/3173574.3173880

Dourish, P. \& S.D. Mainwaring 2012. Ubicomp's Colonial Impulse. In Proceedings of the 2012 ACM Conference on Ubiquitous Computing, 133 - 42. UbiComp' 12, Sep 5 - Sep 8, 2012, Pittsburgh, USA.

https://doi.org/10.1145/2370216.2370238

Dzvimbo, K.P. \& K.C. Moloi 2013. Globalisation and the Internationalisation of Higher Education in Sub-Saharan Africa. South African Journal of Education 33,3: 1 - 16. http://www.scielo.org.za/ (Accessed on 17 January 2019.) https://doi.org/10.15700/201503070808

Gopal, A., L. Beaubien, and T. Marcon. 2002. Old Wolf, New Wool Suit: India, IT, and the Legacy of Colonialism. In ICIS 2002 48: 525 - 32. https://aisel.aisnet.org/icis2002/48/ (Accessed on 30 October 2018.)

Gregor, S. 2006. The Nature of Theory in Information Systems. MISQ 30,3: 611 - 642. https://doi.org/10.2307/25148742

Gruner, S. 2016. Heinz Zemanek's Almost Forgotten Contribution to the Early Philosophy of Informatics. In Proceedings of ACIS 2016: 27th Australasian Conference on Information Systems 1 - 11. Wollongong. https://doi.org/ISBN 978-1-74128-267-2.

Hajibayova, L., W. Buente, L. Quiroga \& S. Valeho-Novikoff. 2016. 
Representation of Kanaka Maoli (Hawaiian) Culture: A Case of Hula Dance. In Proceedings of the 79th ASIS\&T Annual Meeting: Creating Knowledge, Enhancing Lives Through Information \& Technology 128: 1-128:5. ASIST '16. Silver Springs, MD, USA: American Society for Information Science. https://dl.acm.org/doi/10.5555/3017447.3017575

Harvey, A. \& G. Russell-Mundine 2018. Decolonising the Curriculum: Using

Graduate Qualities to Embed Indigenous Knowledges at the Academic Cultural Interface. Teaching in Higher Education 1 - 20.

https://doi.org/10.1080/13562517.2018.1508131

Jansen, J. 2017a. Decolonising the University Curriculum Given a

Dysfunctional School System? (Introduction - Part II). Journal of Education 68: 3 - 13.

Jansen, J. 2017b. The Lost Scholarship of Changing Curricula (Book Review

- Africanising the Curriculum: Indigenous Perspectives and Theories).

South African Journal of Science 113 (5/6).

https://doi.org/10.17159/sajs.2017/a0209

Jooste, N. 2015. South Africa. In De Wit, H. F. Hunter, L. Howard \& E. Egron-

Polak (eds.): Internationalisation of Higher Education. Directorate-

General for Internal Policies, Policy Department B: Structural and Cohesion Policies, Culture and Education, European Parliament. https://doi.org/10.2861/444393

Kawawa, R.M. 1960. Africanisation. Africa South 5,1: 96 - 98.

Leask, B. 2015. Internationalizing the Curriculum. London: Routledge.

Letsekha, T. 2013. Revisiting the Debate on the Africanisation of Higher Education: An Appeal for a Conceptual Shift. The Independent Journal of Teaching and Learning 8,April: 5 - 18.

https://journals.co.za/content/jitl1/8/1/EJC145143

(Accessed on 27 July 2018.)

Lotriet, H. \& M.C. Matthee 2007. Friend or Foe? Locating ICT within the South African Governmental Discourse on Indigenous Knowledge

Systems. In ECIS 2007 (119). https://aisel.aisnet.org/ecis2007/119/ (Accessed on 20 September 2018.)

Mamdani, M. 2018. The African University. London Review of Books 40,14: $29-32$.

Manathunga, C. 2009. Research as an Intercultural 'Contact Zone.' Discourse: Studies in the Cultural Politics of Education 302: 165 - 77. https://doi.org/10.1080/01596300902809161 
Maserumule, M.H. 2015. Why Africa's Professors Are Afraid of Colonial Education Being Dismantled. The Conversation 2015.

http://theconversation.com/why-africas-professors-are-afraid-ofcolonial-education-being-dismantled-50930

(Accessed on 17 September 2018.)

McLaurin, S., T. Carte \& A. Randolph 2015. Undergraduate-to-PhD Project: Examining the Path to Becoming and Remaining an African American Professor in Information Systems. In Twenty-First Americas Conference on Information Systems, 1 - 6.

https://aisel.aisnet.org/amcis2015/SocTech/GeneralPresentations/24/

(Accessed on 17 September 2018.)

Msila, V. 2009. Africanisation of Education and the Search for Relevance and Context. Educational Research and Review 4,6: 310 - 315.

Myers, M.D. \& H.K. Klein. 2011. A Set of Principles for Conducting Critical

Research in Information Systems. MIS Quarterly: Management Information Systems 35 (1). https://doi.org/10.2307/23043487

Ndlovu-Gatsheni, S.J. 2018. Epistemic Freedom in Africa: Deprovincialization and Decolonization. Abingdon: Routledge.

Ngwenyama, O. \& S. Klein 2018. Phronesis, Argumentation and Puzzle Solving in IS Research: Illustrating an Approach to Phronetic IS Research Practice. European Journal of Information Systems, 1 - 20.

https://doi.org/10.1080/0960085X.2018.1435229

Nwokoye, C.H., V.E. Ejiofor, R.O. Njideka \& N. Mbeledeogu 2016. The Topicality of Agent-Based Modeling/Multi Agent Systems in Human Computer Interaction Research: An African Perspective. In Proceedings of the First African Conference on Human Computer Interaction, 80 - 91. AfriCHI'16. November 21-25, 2016, Nairobi, Kenya. https://doi.org/10.1145/2998581.2998593

Oates, Briony J. 2006. Researching Information Systems and Computing. Los Angeles, CA: Sage.

Phahlamohlaka, L.J. \& J.H. Kroeze. 2005. Sacred Space in Cyber Space: An African Perspective. Journal for Semitics 14 (2): 413 - 40.

Ponelis, S.R., M.C. Matthee, S. Buckley, J.H. Kroeze, I.M. Venter, and P.D. Pretorius. 2012. Building Capacity and Developing Human Capital: An Exploration of Curriculum Development in ICT Programmes at South African Universities. In SIG GlobDev Fifth Annual Workshop (3). Orlando, FL. https://aisel.aisnet.org/globdev2012/3/ 
(Accessed on 17 September 2018.)

Popper, Karl. 1981. The Importance of Critical Discussion: An Argument for Human Rights and Democracy. In Shearmur, J. \& P.N. Turner. After the Open Society: Selected Social and Political Writings (2008). London: Routledge.

Popper, K. \& N. McIntyre 1983. The Critical Attitude in Medicine: The Need for a New Ethics. In Shearmur, J. \& P.N. Turner. After the Open Society: Selected Social and Political Writings (2008). London: Routledge.

Prinsloo, Paul. 2010. Some Reflections on the Africanisation of Higher Education Curricula: A South African Case Study. Africanus 1,1: 19 - 31. (Accessed on 17 July 2018.)

http://reference.sabinet.co.za/sa_epublication_article/canus_v40_n1_a3

Prinsloo, P. 2016. Curricula as Contested and Contesting Spaces: Geographies of Identity, Resistance and Desire (Draft). (Keynote, Transforming the Curriculum: South African Imperatives and 21st Century Possibilities, University of Pretoria, 1 February 2016).

Ridings, S., L. Simpson, B. Leask, M. Freeman, P. Ramburuth, L. Treleaven, C. Sykes \& M. Fletcher 2008. Developing Intercultural Competence: ALTC Project Update. Herdsa News.

Rizvi, F. \& L. Walsh 1998. Difference, Globalisation and the Internationalisation of Curriculum. Australian Universities' Review 2: 7 - 11.

Topi, H., H. Karsten, S.A. Brown, J.A. Carvalho, B. Donnellan, J. Shen, B.C.Y. Tan \& M.F. Thouin. 2017. MSIS 2016 Global Competency Model for Graduate Degree Programs in Information Systems. Communications of the Association for Information Systems 40,1: MSIS-i-MSIS-107.

https://doi.org/10.17705/1CAIS.04018

(Accessed on 20 September 2018.)

Topi, H., J.S. Valacich, R.T. Wright, K.M. Kaiser, J.F. Nunamaker, J.C. Sipior, \& G-J. De Vreede 2010. IS 2010: Curriculum Guidelines for Undergraduate Degree Programs in Information Systems.

https://doi.org/10.17705/1CAIS.02618

Tsey, Komla. 2010. Making Social Science Matter? Case Studies from Community Development and Empowerment Education Research in Rural Ghana and Aboriginal Australia. Asian Social Science 6,2001: 3 12. https://doi.org/10.5539/ass.v6n1p3

Tsey, K., D. Patterson, M. Whiteside, L. Baird \& B. Baird 2002. Indigenous Men Taking their Rightful Place in Society? A Preliminary Analysis of a 
Participtory Action Research Process with Yarrabah Mens' Health Group. Australian Journal of Rural Health 10,6: 278 - 84.

https://doi.org/10.1046/j.1440-1584.2002.00491.x

Tsibolane, P. 2016. Towards a Conceptual Framework for Social Wellbeing through Inclusive Frugal ICT Innovation in Postcolonial Collectivist Contexts. In CONF-IRM 2016 Proceedings (8).

https://aisel.aisnet.org/confirm2016/8/

(Accessed on 19 September 2018.)

Tsibolane, Pitso, and Irwin Brown. 2016. Principles for Conducting Critical Research Using Postcolonial Theory in ICT4D Studies. In GlobDev 2016(3): Reflecting on Appropriate Global Development and the Role of ICTs and Digital Innovation. http://aisel.aisnet.org/globdev2016/3 (Accessed on 19 September 2018.)

Villiers, Carina De, Roy Johnson, and Phillip Cremer. 2012. South African ICT Skills Deficiency. In Proceedings in Eighteenth Americas Conference on Information Systems 16: 9 - 12.

https://aisel.aisnet.org/amcis2012/proceedings/ICTinGlobalDev/16/ (Accessed on 17 September 2018.)

Waldron, Rupert. 2017. Positionality and Reflexive Interaction: A Critical Internationalist Cultural Studies Approach to Intercultural Collaboration. Innovations in Education and Teaching International 54,1: 12 - 19. https://doi.org/10.1080/14703297.2016.1156010

Westhuizen, M. Van der, T. Greuel, and J.W. Beukes. 2017. Are We Hearing the Voices? Africanisation as Part of Community Development. HTS Theological Studies 73,3: 1 - 19. https://doi.org/10.4102/hts.v73i3.4512

Zemanek, H. 1966. Semiotics and Programming Languages. Communications of the ACM 9,3: 139 - 143. https://doi.org/10.1145/365230.365249

Zemanek, Heinz. 1974. The Computer: A Mechanical Device in a Live Environment. In 6th Australian Computer Conference 894 - 911.

Jan Hendrik Kroeze

School of Computing College of Science, Engineering and Technology University of South Africa Science Campus, Roodepoort kroezjh@unisa.ac.za 